\title{
Operational and Safety Assessment of Motorised Three-Wheel Vehicles for Public Transport in the Tamale Metropolis
}

\author{
*Lukuman Wahab ${ }^{1}$ Mohammed Salifu ${ }^{2}$ \\ ${ }^{1}$ Tamale Polytechnic, Tamale, Ghana, School of Engineering \\ ${ }^{2}$ Kwame Nkrumah University of Science \& Technology, Kumasi, Ghana, Department of Civil Engineering \\ *luqremi@yahoo.com
}

\begin{abstract}
Motorised three-wheel vehicles are important modes of transportation in the Tamale metroplis because they provide alternative mobility solutions for low and middle income earners and fill the gaps in transportation systems in Ghana. The fact that motorised three-wheel vehicles are inexpensive to manufacture, sell, operate and repair compared to cars have also catalysed the surge in their ownership. This study evaluates the operations and safety of motorised three-wheel vehicles as a means of public transport for goods and humans in the Tamale Metropolis. To achieve this objective, a manual traffic classification count was carried out on the following main roads: Hospital Road, Bolgatanga Road, Choogu Road and Nyohini Road within the study area; a survey questionnaire was designed to elicit information from operators as well as users of motorised three-wheel vehicles. Road traffic crashes data were obtained and analysed. Direct field observations were also carried out along selected roads. The manual traffic classification count revealed that motorised three-wheel vehicles constitute the third most significant mode of transport in the study area whereas light vehicles and motorcycles are first and second respectively. Additionally, operation of motorised three-wheel vehicles provides employment or livelihood to people who are otherwise unemployable and have families to take care of. In terms of safety, $94.6 \%$ are completely unlicensed, 3.1\% have motorcycle license, $1.5 \%$ have tractor operator license and $0.8 \%$ have driving license. Lack of required driving skills could be one of contributing factors of crashes in the study area. The vehicles also stop or park at unauthorised places, leading to congestion and traffic management problems on roads. It is therefore recommended that the operation of motorised three-wheel vehicles within Tamale Metropolis Area be regulated and designated spaces provided for parking.
\end{abstract}

Keywords: Motorised three-wheel Vehicles, Public Transport, Operational, Safety; Tamale

\section{Introduction}

In cities of developed nations, good transportation mix generally exists, that is, the presence of nonmotorised and private motor vehicles and a good range of public transportation system notably buses in different sizes as well as choices in trains and monorails (Chanchani \& Rajkotia, 2012). On the other hand, in the case of public transportation, the opposite seems to be happening in most cities of developing countries, like Ghana. The lack of common or traditional forms of public transport network and infrastructure such as mass public transportation is usually substituted with other innovative modes of public transportation such as motorcycle taxis (Kumar, 2011). Motorised threewheel vehicles cater for the needs of low and middle income sectors and often fill the gaps in urban transport systems when public transport systems are inefficient and not integrated (Civitas Consultancies Pvt Ltd, 2010; Innovative Transport Solutions 2009). Several factors influence the growth of motorised three-wheelers such as the inability of public transport systems to keep up with increasing demand for mobility, lower acquisition cost and better fuel economy compared to cars. These factors have increased the surge in motorised three-wheel vehicle ownership (CAI-Asia Center, 2011; Civitas 
Consultancies Pvt Ltd, 2010; Innovative Transport Solutions 2009).

A decline in organized public transport systems has led to rapid growth in non-conventional means of public transport, initially provided by minibuses and shared taxi/vans, and more recently by commercial motorcycles (Kumar, 2011). Unlike other cities in Ghana, ownership and use of motorised three-wheel vehicles for public transport is common in Tamale.

The city faces challenges that are common to many developing cities including transportation, pollution and poverty. Among these, transportation is a major challenge because apart from taxis there is no commercial public transport such as small and medium buses popularly known as 'Trotro' by most Ghanaians. However, over the past years there has been a significant growth in the use of motorised three-wheel vehicles popularly called 'motor king' as a commercial public transport mode. While offering certain transport advantages in the form of easy manoeuvrability, ability to travel on poor roads, door-to-door services, demand responsiveness, commercial motorised three-wheel vehicles are believed to have led to an increase in road accidents, traffic management problems, pervasive noise and increase in air pollution and greenhouse gas emissions (Chanchani \& Rajkotia, 2012; CAI-Asia Center, 2011; Hook \& Fabian, 2009; Innovative Transport Solutions 2009).

CAI-Asia Center (2011) reported that several cities have issued policies and regulations to improve or restrict the operations of motorised three-wheel vehicles in Asian cities and countries. Examples of such restrictions are ban on motorised three-wheel vehicles on certain roads, capping the number of motorised three-wheel vehicles, ban on parking in specific areas and providing exclusive lanes. These policies and regulations seek to improve safety, mitigate congestion and traffic management problems and compliance with international or national ambient air quality or noise standard.

\subsection{Objectives of the Study}

The main aim of the study was to assess the operational regime and safety challenges of motorised three-wheel vehicles being used as a means of public transport in the Tamale Metropolis and surrounding areas.

In order to achieve this aim, the research sought to: assess the utility and significance of motorised threewheel vehicles as a mode of public transport in the study area, assess the safety of motorised three-wheel vehicles for public transport and identify operational factors and challenges to be addressed through policy and enforcement.

\section{Methodology}

\subsection{Data collection}

Data was collected through multi-approach techniques. These included questionnaire surveys, manual classified traffic count, direct observation and in-depth interviews.

\subsubsection{Manual Classified Traffic count}

Traffic count of the different modes of motorised urban transport that exist in the Tamale Metropolis was conducted at selected road sections that lead to the central business district of Tamale. These roads were selected based upon the degree of congestion observed especially at peak hours. Apart from Motorcycle and motorised three-wheel vehicles, other vehicles were classified into three main categories. These categories are Light, Medium and Heavy Vehicles.

Traffic counts were conducted on the following main roads: Hospital Road, Bolgatanga Road, Choogu Road and Nyohini Road.

The counts were conducted on Tamale market (day) because from observation, the day represents peak patronage of the services of motorised threewheelers. Manual classified directional counts were conducted at 15 minutes interval from 10:00 AM to 1:00 PM and 3:00 PM to 6:00 PM. No count was done outside this time range, because of limited financial resources and also use of the motorised three-wheel vehicles is rare. Two enumerators were assigned to each site, one for each direction of travel to reduce the error in recording.

\subsubsection{Questionnaire Surveys}

Questionnaires were designed to elicit information from the operators (drivers) as well as users (passengers) of the motorised three-wheel vehicles. This was done to obtain data from the operators on their backgrounds, daily working hours, type of service, sales, experience, number of crashes they have been involved in and time of crash. Similarly, data were collected from the users of this mode of transport with respect to their reasons for their choice of this mode, safety and other related issues.

\subsubsection{Direct Observation}

Field observations were carried out along some selected roads in the study area to get first hand information on impedance to traffic flow caused by the presence of motorised three-wheel vehicles on the roads. This was done by taking a ride with a motorcycle along the selected roads in the study area. The different brands of motorised three-wheel 
vehicles such as Motor-king, Apsonic, OG, and Loujia were also noted.

\subsubsection{In-Depth Interviews}

Spot interviews using pre-prepared questionnaires were conducted with drivers from a cross section of the driving public in the study area. Their responses to questions relating to the presence of the motorised three-wheel vehicles on the roads and their effect on their movements were noted.

Consultations were held with the Department of Urban Roads, National Road Safety Commission (NRSC), Transportation Unions, relevant Metropolis Assembly staff, as well as randomly selected road users to explore their opinions on the issues that affect safety and traffic management due to the presence of the motorised three-wheel vehicles on the road network of the Tamale Metropolis.

Discussion was held with a company called Motor King Limited. This company is the importer of the most common motorised three-wheel vehicles in Tamale. The main aim of this discussion was to find out why the company is not importing auto rickshaw which is more comfortable and safe.

\subsubsection{Road Traffic Crash Data}

Road traffic crash data for the research was collected from the Building and Road Research Institute (BRRI) accident database in Kumasi, the national data bank for road traffic crashes in Ghana. The data for the study area was obtained by querying the Micro-Computer Accident Analysis Package (MAAP). However the data related to the motorised three-wheel vehicles could not be obtained directly; it was incorporated into the motorcycle data. The data covered the period of 2009-2011.

\subsection{Sampling and Sampling Procedure}

A random sampling method was adopted; the only criteria for selection being that the operator was the person driving the motorised three-wheel vehicles for commercial purpose and the criteria for the selection of passenger was that the person used the motorised three-wheel vehicles for travel at least once a month. Questionnaires were administered to 260 operators who were driving motorised three-wheel vehicles and 100 passengers. Responses from the survey revealed that 109 were owner-operators while the remaining 151 rented motorised three-wheel vehicles on daily basis.

\subsection{Analysis of the Data}

The collected data were analysed using Microsoft Excel and descriptive statistics such as percentage, mean and mode were used.

Table 1

Summary of manual classified traffic count

\begin{tabular}{|c|c|c|c|c|c|c|c|}
\hline \multirow{2}{*}{\multicolumn{2}{|c|}{ VEHICLE TYPE }} & \multicolumn{5}{|c|}{ VEHICLE CATEGORY ANALYSES } & \multirow[b]{2}{*}{ TOTAL } \\
\hline & & Motor & Motorised & Light & Medium & Heavy & \\
\hline \multirow{2}{*}{ Hospital Road } & Volume & 2257 & 316 & 4635 & 174 & 74 & 7456 \\
\hline & $\%$ of Total & 30.3 & 4.2 & 62.2 & 2.3 & 1.0 & 100.0 \\
\hline \multirow{2}{*}{ Choogu Road } & Volume & 4998 & 473 & 5724 & 144 & 81 & 11420 \\
\hline & $\%$ of Total & 43.8 & 4.1 & 50.1 & 1.3 & 0.7 & 100.0 \\
\hline \multirow{2}{*}{$\begin{array}{c}\text { Bolgatanga } \\
\text { Road }\end{array}$} & Volume & 2597 & 240 & 3768 & 481 & 344 & 7430 \\
\hline & $\%$ of Total & 35.0 & 3.2 & 50.7 & 6.5 & 4.6 & 100.0 \\
\hline \multirow[b]{2}{*}{ Nyohini Road } & Volume & 3383 & 628 & 3634 & 262 & 66 & 7973 \\
\hline & $\begin{array}{l}\% \text { of } \\
\text { Total }\end{array}$ & 42.4 & 7.9 & 45.6 & 3.3 & 0.8 & 100.0 \\
\hline \multirow{2}{*}{ TOTAL } & Volume & 13235 & 1657 & 17761 & 1061 & 565 & 34279 \\
\hline & $\begin{array}{l}\% \text { of } \\
\text { Total }\end{array}$ & 39 & 5 & 52 & 3 & 2 & 100.0 \\
\hline
\end{tabular}




\section{Results and Discussions}

\subsection{Traffic Composition}

Table 1 above shows the result of a six-hour manual classified traffic count conducted along the main roads that lead to the central business district of the study area. The highest traffic volume of 11,420 vehicles was recorded on the Choggu Road, $4.1 \%$ of which was made up of motorised three-wheel vehicles. The lowest traffic volume of 7,430 vehicles was recorded on the Bolgatanga Road, $3.2 \%$ of which was made up of motorised three-wheel vehicles. However the highest volume of 628 motorised three-wheel vehicles was recorded on the Nyohini Road and represented $7.9 \%$ of the vehicles along the road. For the combined traffic, Figure 1 indicates that motorised three-wheel vehicles constituted $5 \%$ of the traffic stream on the four roads.

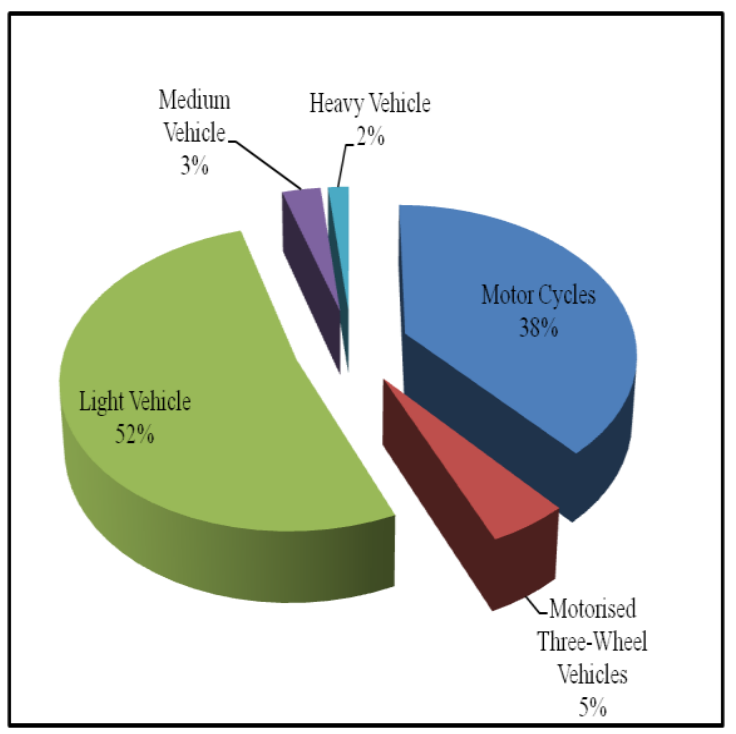

Fig. 1: Vehicle Category Analyses

It is also observed from the figure that motorised three-wheel vehicles are the third most significant mode of transport in the Tamale Metropolitan Area.

\subsection{Backeground of Motorised Three-Wheel Vehicles Operators}

Figure 2 shows the age distribution of the drivers/operators of motorised three-wheel vehicles interviewed in this study.

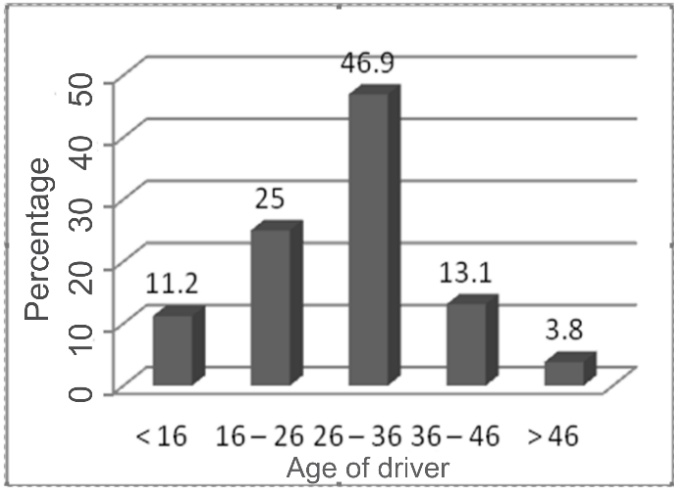

Fig. 2: Age distribution of drivers

The figure reveals that $11.2 \%$ of the drivers were less than sixteen (16) years of age while 3.8 percent were over forty-six (46) years of age. Nearly $50 \%$ of the drivers were within the age group of 26-36 years. All two hundred and sixty (260) drivers interviewed were males.

Figure 3 shows the distribution of the years of experience of the drivers of the motorised threewheel vehicles in the study area.

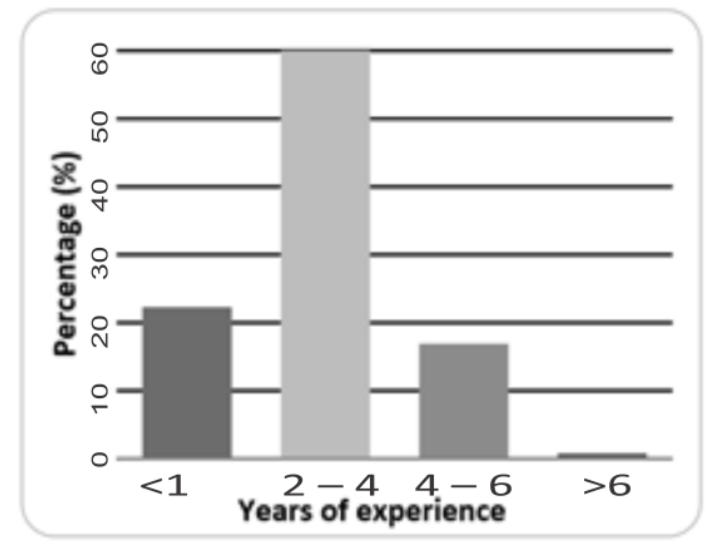

Fig. 3: Distribution of years of experience of drivers

The figure reveals that $22.3 \%$ of the drivers have less than one year of experience, $60 \%$ have experience between 2-4 years and 16.9\% between 4-6 years of experience. Therefore, more than $50 \%$ of the drivers have less than 4 years experience.

Table 2 shows the background of drivers that were interviewed during the field survey; their marital status and educational level. 
Table 2

Marital status and education level of drivers

\begin{tabular}{lll}
\hline & Frequency & $\begin{array}{c}\text { Percentage } \\
(\%)\end{array}$ \\
\hline Marital Status & & \\
Married & 165 & 63.5 \\
Not married & 95 & 36.5 \\
& & \\
Educational Level & & \\
No formal & 121 & 46.5 \\
education & 87 & 33.5 \\
Primary & 28 & 10.8 \\
Junior Secondary & 24 & 9.2 \\
SHS/ Technical & & \\
& & \\
\hline
\end{tabular}

As can be seen from the table, a little over $60 \%$ of the drivers are married and close to $50 \%$ have no formal education. Clearly, a substantial proportion of the drivers have no employable skills. This is an important socio-economic dimension to the operation/ownership of motorised three-wheel vehicles. The findings above supports that of Kumar (2011), who established that, commercial motorcycles provide employment for a large number of; majority of operators are young ( 85 percent belong to the age group 25-45). Over 70 percent of the motorcycle drivers possess junior or secondary/technical education, and have been operating a motor-cycle for over six years

Table 3 illustrates the overall license status of operators that were interviewed during the field survey.

Table 3

Usage of license for driving motorised three-wheel vehicles

\begin{tabular}{ccc}
\hline Licence type & Frequency & $\begin{array}{c}\text { Percentage } \\
(\%)\end{array}$ \\
\hline No license & 246 & 94.6 \\
$\begin{array}{c}\text { Motorcycle } \\
\text { License } \\
\text { Tractor } \\
\text { operator } \\
\text { license } \\
\text { Driving license }\end{array}$ & 8 & 3.1 \\
\hline
\end{tabular}

The table reveals that of the 260 drivers reached during the survey, $94.6 \%$ are completely unlicensed and only $3.1 \%$ have motorcycle license, $1.5 \%$ have tractor operator license and $0.8 \%$ have driving license. Lack of the required driving licence and hence the required driving skills could be one of the contributing factors of crashes in the study area.

\subsection{Economic of operating motorised three-wheel vehicles}

The responses from the survey indicated that one hundred and nine out of the two hundred and sixty respondents owned motorised three-wheel vehicles they operated while the remaining rented them on daily basis.

Table 4 shows the economics associated with the operation of motorised three-wheel vehicles in the study area.

Table 4

\begin{tabular}{ccc}
\multicolumn{3}{l}{ Operating Characteristics and Associated Economics } \\
\hline Variables & Mean & $\begin{array}{c}\text { Standard } \\
\text { deviation }\end{array}$ \\
\hline $\begin{array}{c}\text { Amount earned daily } \\
\text { (GHC) }\end{array}$ & 59.02 & 8.09 \\
Rent paid daily (GHC) & 14.91 & 2.02 \\
Daily working hours & 8.47 & 0.10 \\
\hline
\end{tabular}

The mean of daily earning is GHC 59.02 and the mean for daily rent is GHC 14.91. This reveals that, owning and renting a motorised three-wheel vehicle provide investment for some people and livelihood for others.

\subsection{Traffic crashes}

Out of the forty- six (46) crashes, thirty-six (36) crashes occurred during the daytime, representing $78 \%$ of the forty- six (46) crashes while the remaining ten (10) crashes occurred at night, representing $22 \%$ of the forty- six (46) crashes. Only four (4) of these crashes were reported to the police, representing $9 \%$ of the forty-six accidents. People sustained various degrees of injuries in twelve (12) of these crashes representing $26 \%$.

\subsection{Usage of Crash Helmet}

In terms of ownership of crash helmets, only $6.5 \%$ of the two hundred and sixty motorised three-wheel vehicle drivers interviewed did not have motorcycle helmets. The extent of use of helmets by the drivers is shown in Figure 4. 


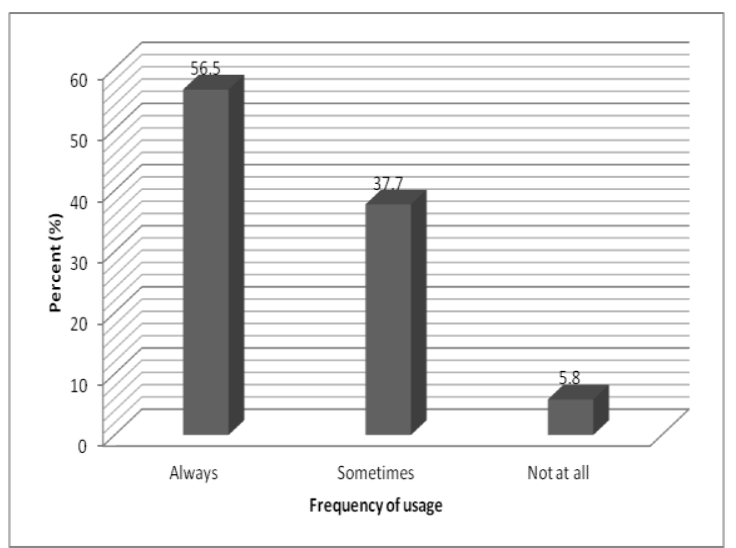

Fig. 4: Use of motorcycle helmets

$56.5 \%$ of the drivers of motorised three-wheel vehicles said they always use helmet while $37.7 \%$ sometimes use helmets. It is clear that a significant population of those who have helmets did not always use them. Most of the drivers of motorised threewheel vehicles confirmed that they are aware of the safety benefits of using helmets yet they feel reluctant to use them.

\subsection{Challenges faced by drivers of motorised three-wheel vehicles}

Figure 5 shows some of the challenges faced by drivers of motorised three-wheel vehicles in the study area.

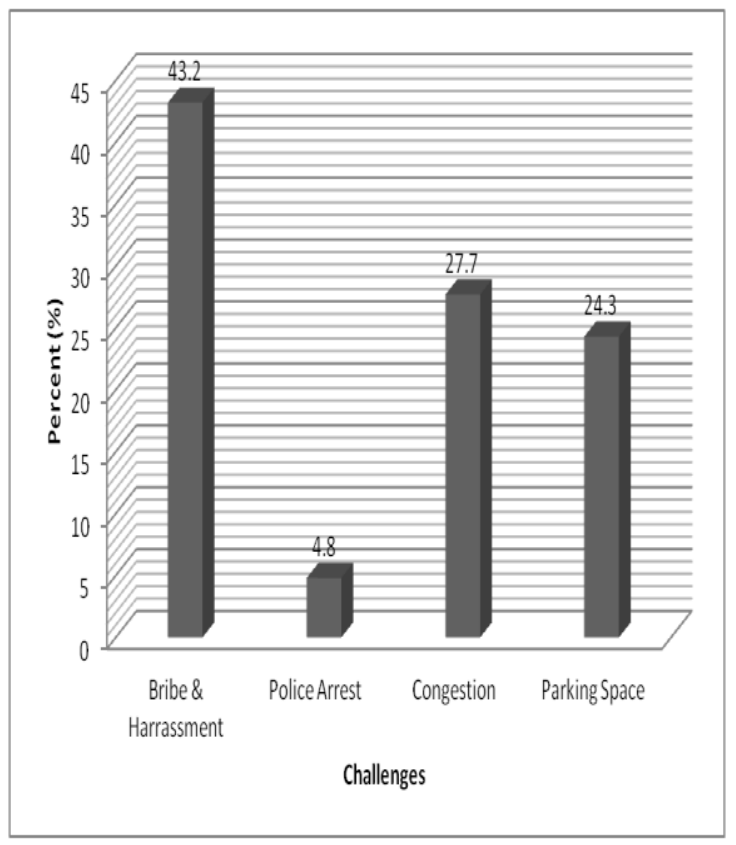

Fig. 5: Challenges associated with the use of motorised three-wheel vehicles

The survey findings reveal that $43.2 \%$ of drivers interviewed complained about bribe and harassment from the Police, $27.7 \%$ complained about congestion on the road, $24.3 \%$ complained about parking problems and $4.8 \%$ complained about arrest from Police.

At the end of the interview, the survey instrument gave drivers an opportunity to suggest or comment on anything they thought was important but had been left out or not well addressed. A significant proportion of the drivers came up with the issue of disrespect by passengers due to nonrecognition of their profession. They also expressed a need for parking space from Tamale Metropolis Assembly.

\subsection{Background of passengers of motorised three-wheel vehicles}

Table 5 gives full details about the background of passengers of motorised three-wheel vehicles interviewed.

Table 5

Background of motorised three-wheel vehicles passengers

\begin{tabular}{ccc}
\hline Age (years) & Frequency & Percentage (\%) \\
\hline & & \\
$16-26$ & 10 & 10.0 \\
$26-36$ & 55 & 55.0 \\
$37-48$ & 15 & 15.0 \\
$>48$ & 20 & 20.0 \\
\hline
\end{tabular}

The average age of the respondents was 31 years with a standard deviation of 1.67 years. $55 \%$ of these motorised three-wheel vehicle passengers were within 26 to 36 years age cohort. All the respondents were female traders.

\subsection{Frequency of usage of motorised three-wheel vehicles}

Figure 6 below illustrates the frequency of usage of motorised three-wheel vehicles in the study area. Out of 100 passengers interviewed, 30\% said they use this type of vehicle daily, $15 \%$ twice a week and $55 \%$ use it once a week. 


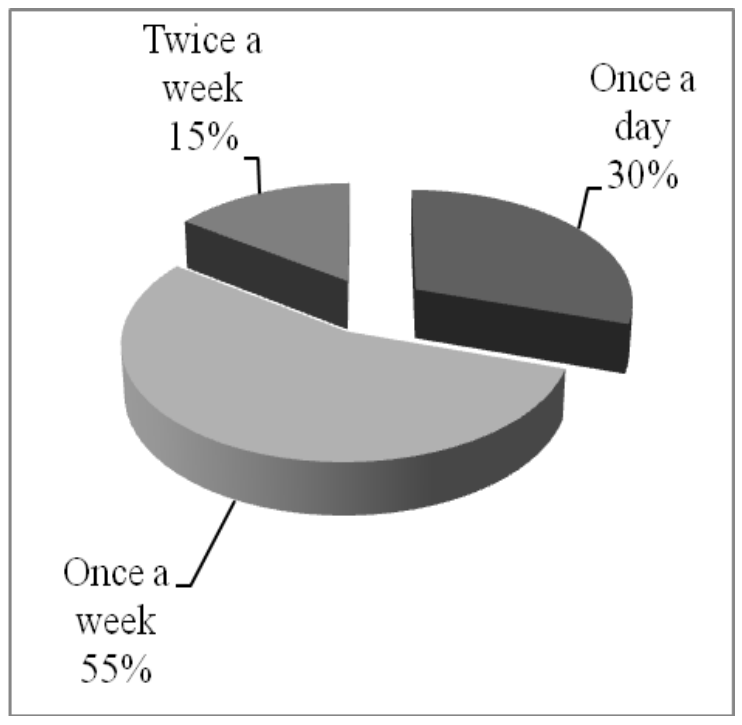

Fig. 6: Frequency of usage of motorised three-wheel vehicles

In terms of reasons for the choice of this mode of transport, Figure 7 shows that $37.7 \%$ of respondents prefer motorised three-wheelers because they can sit inside with their goods, $24.5 \%$ said they prefer it because it provides door-to-door services and $22.7 \%$ prefer it because it is cheaper whereas $15.1 \%$ prefer it because it is faster.

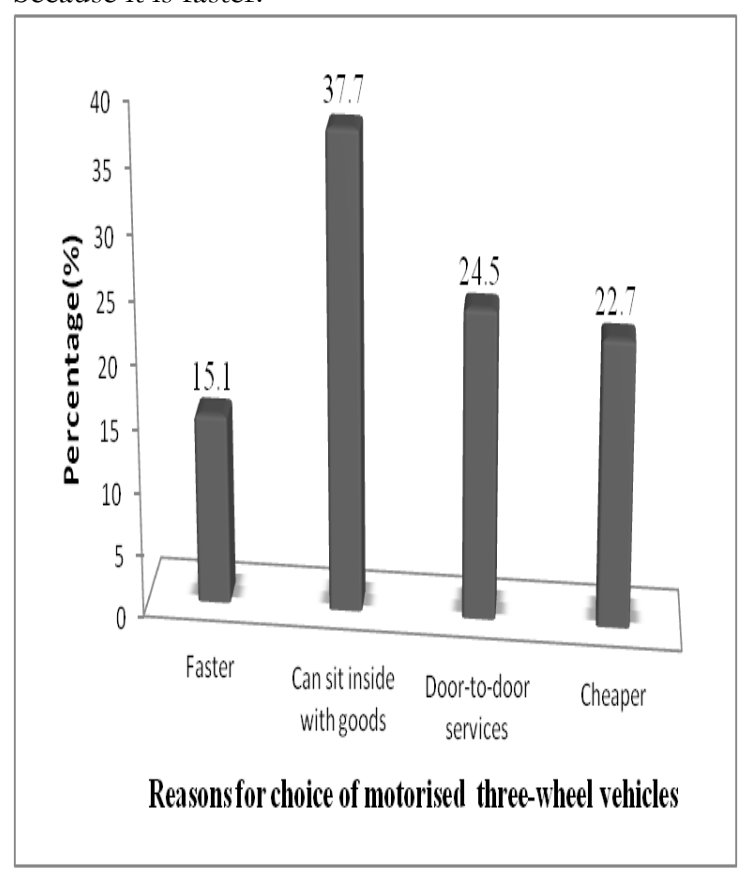

Fig.7: Reasons for choice of motorised three-wheel vehicles

\subsection{Parking for motorised three-wheelers}

Field observations indicated that there are no designated parking spaces for motorised three-wheel vehicles in Tamale thus drivers park on any available space such as pedestrian walkways, bicycle lanes, shoulders and along carriageways.

Figures 8 and 9 show motorised three-wheel vehicles parked at unauthorised places.

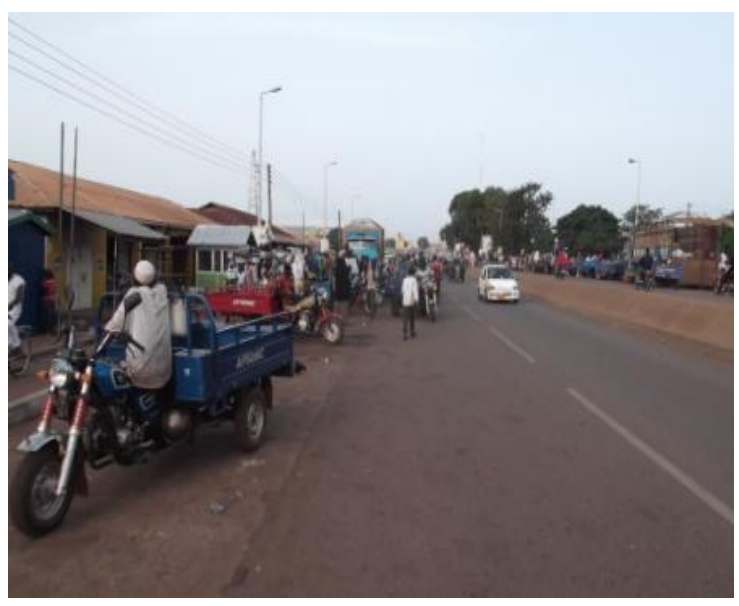

Fig. 8: Motorised three-wheel vehicles parked at a bus bay

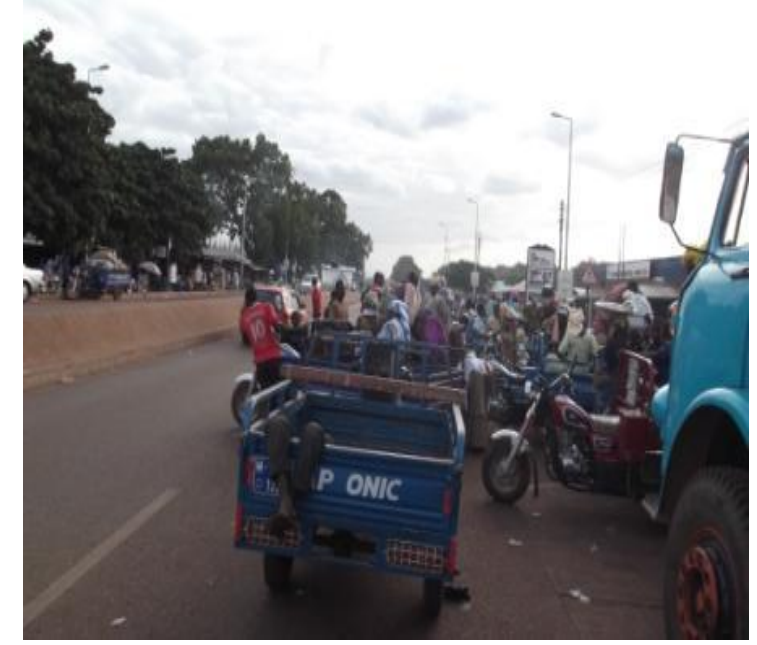

Fig. 9: Motorised three-wheel vehicles parked on a carriageway

It was noted that the presence of the motorised three-wheel vehicles at unauthorised parking places impede the movement of other road users along the roads.

In addition to the parking problems, other road users interviewed (taxis drivers and private car users) complained of the poor driving habits of the motorised three-wheel vehicles drivers and their disregard for traffic regulations. It was made clear that the indiscipline and reckless driving mostly contribute to conflicts among road users during peak hours especially on Tamale market days. 


\subsection{Road Traffic Crash Characteristics}

As already stated, the road traffic crash data of Motorised three-wheel vehicles could not be obtained directly from the database of the BRRI, as the available data does not distinguish between motorcycles and motorised three-wheel vehicles.

During the manually classified traffic count, the numbers of motorcycles captured was 13,235 as against 1,657 motorised three-wheel vehicles. This means that the ratio between the motorised threewheel vehicles and the motorcycles is 1:8. It is therefore assumed that for every nine motorcycle accidents in the BRRI database, one would involve a motorised three-wheel vehicle.

\subsubsection{Traffic crashes by vehicle type}

Figure 10 displays the number of road traffic crashes by vehicle type in the Tamale Metropolitan Area from 2009 to 2011.

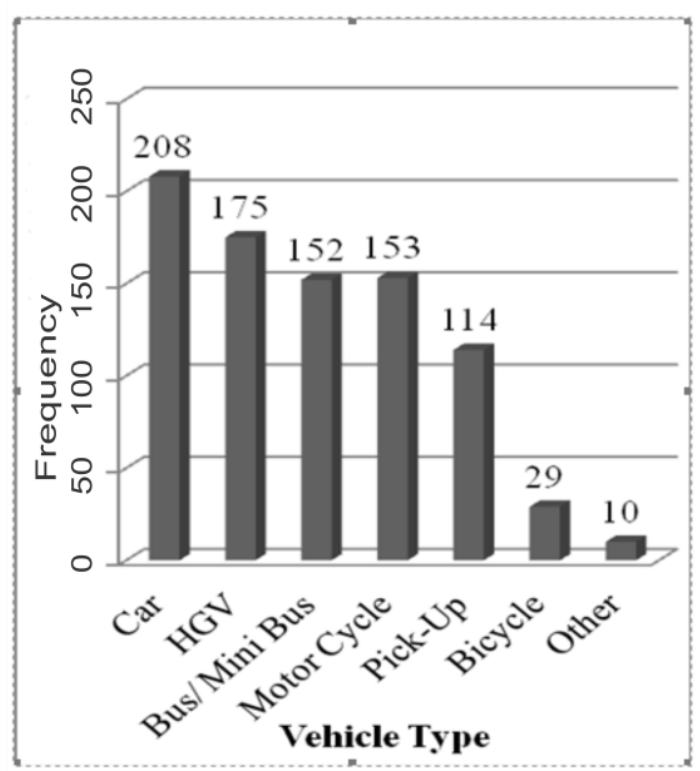

Fig. 10: Road traffic crashes by vehicle type in the

Tamale Metropolitan Area (2009-2011)

As shown by the figure, motorcycles ranked third in terms of crashes in the study area.

\subsubsection{Crash type by casualty class}

Examination of crash casualty class records of the study in Table 6 shows a total of 110 casualties for 3 years.
Table 6

Number of motorcycle related road traffic crashes by casualty class in the Tamale Metropolitan Area (20092011)

\begin{tabular}{ccccc}
\hline YEAR & \multicolumn{3}{c}{ CASUALTY CLASS } & Total \\
\cline { 2 - 3 } & $\begin{array}{c}\text { Driver } \\
\text { (Ride) }\end{array}$ & $\begin{array}{c}\text { Pillion } \\
\text { Rider }\end{array}$ & Pedestrian & \\
2009 & 20 & 2 & 2 & 24 \\
2010 & 36 & 11 & 4 & 51 \\
2011 & 26 & 5 & 4 & 35 \\
Total & 82 & 18 & 10 & 110 \\
\%ofTotal & 75 & 16 & 9 & 100 \\
\hline
\end{tabular}

In all, 82 riders sustained various degrees of casualties representing $75 \%$, followed by drivers with $16 \%$ and pedestrians, 9\%. The table indicates that with Motorcycle related crashes by casualty class, of the crashes that were affected, pedestrians represents the least, whereas drivers (riders) were affected the most represented.

\subsubsection{Crash type by collision}

Table 7 gives all motorcycle related road traffic crashes by collision that occurred within the period of analyses in the study area. 
Table 7

Number of motorcycle related road traffic crashes by collision in the Tamale Metropolitan Area (2009-2011)

\begin{tabular}{|c|c|c|c|c|c|}
\hline \multirow[t]{2}{*}{ COLLISION TYPE } & \multicolumn{2}{|c|}{ Year } & & \multirow[t]{2}{*}{ Total } & \multirow[t]{2}{*}{$\%$ of Total } \\
\hline & 2009 & 2010 & 2011 & & \\
\hline Head On & 3 & 3 & 1 & 7 & 8 \\
\hline Rear End & 7 & 13 & 11 & 31 & 33 \\
\hline Right Angle & 5 & 6 & 9 & 20 & 22 \\
\hline Side Swipe & 4 & 12 & 8 & 24 & 26 \\
\hline Ran Off Road & 1 & 1 & 0 & 2 & 2 \\
\hline Hit Object Off Road & 0 & 0 & 1 & 1 & 1 \\
\hline Hit Parked Vehicle & 1 & 0 & 0 & 1 & 1 \\
\hline Hit Pedestrian & 2 & 2 & 3 & 7 & 8 \\
\hline Total & 23 & 37 & 33 & 93 & 100 \\
\hline
\end{tabular}

As shown by the table, occurrence of rear end Collisions has been found to be most dominant in motorcycle related road traffic crashes. During the period 2009-2011, right angle Collision were consistently on the increase. From the table, $33 \%$ of all crashes involved rear end, $26 \%$ side swipe and $22 \%$ right angle.

\section{Conclusion}

The study revealed that motorised three-wheel vehicles constituted the third most significant mode of transport in the Tamale Metropolis yet their operation is not regulated. The operation of the motorised three-wheel vehicles provides employment opportunity. Majority of the operators are in the age group of 26-36 years, have less than 4 years experience and they are predominantly male. The education level of most of the operators varies between no formal education and secondary/technical school. $46.5 \%$ of operators had no formal education while $9.2 \%$ of them are secondary/technical graduates.

The study identified Motorised three-wheel vehicles as the key mode of transport in and around the rural/peri-urban areas of Tamale, including Nyankpala, Kpakayili, Bangvim and Gurugu. 37.7\% of the users prefer the motorised three-wheelers because they can sit inside with their goods, $24.5 \%$ prefer it because it provides door-to-door services and $22.7 \%$ prefer it because it is cheaper whereas others prefer it because it is faster.

Arguing from the results of this study, there is no designated place that can serve as a terminal for motorised three-wheel vehicles commuting between Tamale and key peri-urban and rural communities, thus creating traffic management problems along key road corridors in the Metropolis.
Ninety-four (94)\% of motorised three-wheel vehicles are completely unlicensed while only $3 \%$ had motorcycle license. Lack of required driving licence

and the required driving skills could be one of the contributing factors of crashes in the study area.

It is recommended that the operation of Motorised three-wheel vehicles within the Tamale Metropolitan Area and the peri-urban areas needs to be regulated by the appropriate authorities. Hence, planning and policies have to follow the regulation adopted by Asian countries in which Motorised three-wheel vehicles are banned from certain key road corridors in urban areas instead of total prohibition in the urban area.

\section{References}

CAI-Asia Center. (2011). Managing two and three wheelers in Asia. Clean Air Initiative for Asian Cities. Pasig City, pp. 1-6.

Chanchani, R., \& Rajkotia, F. (2012). A study of the Autorickshaw Sector in Bangalore City - Suggestions for Improved Gorvernance. Center for Infrastructure, Sustainable Transport and Urban Planning, Bangalore, pp. 1-12.

Civitas Consultancies Pvt Ltd. (2010). Study on the Autorickshaw Sector in Chennai. Chennai City Connect Foundation, Chennai, pp. 20-25.

Hook, W., \& Fabian, B. (2009). The best practices in regulation and design of Motorised and NonMotorised two-and-three-wheelers in Urban Traffic. Institute for Transportation and Development Policy, New Delhi, pp. 3-10.

Innovative Transport Solutions. (2009). Two and Three Wheelers in India. New Delhi: International Council for Clean Transportation \& The Institute for Transport and Development Policy, New Delhi, pp. 10-16. 
Kumar, A. (2011). Understanding the emerging role of motorcycles in African cities A political economy perspective. Discussion Paper No. 13 Urban Transport Series. Sub-Saharan Africa

Transport Policy Program (SSATP), pp. 1-12. 